\title{
Modality and evidentiality: a discussion of philosophical and formal aspects
}

\author{
Modalidade e evidencialidade: \\ uma discussão sobre aspectos filosóficos e formais
}

Monica Monawar

Universidade Federal de Santa Catarina - Santa Catarina - Brasil

\begin{abstract}
This work discusses biological, philosophical and formal notions that underlie current approaches on natural language modality. The aim is to promote a theoretical debate of some of the ontological and methodological components that are sometimes taken for granted in current literature on the topic. A discussion on the evolution of language in connection to modality in terms of planning and displacement is promoted, followed by Lewis's and Stalnaker's discussions on possible worlds theory. Finally, a comparative approach on Lewis's and Stalnaker's perspectives on knowledge and belief is built in order to create a foundation for further readings on the topic of modals and evidentials.
\end{abstract}

Keywords: Modality; Evidentiality; Philosophy of language; Formal semantics

Resumo: Este trabalho discute noções biológicas, filosóficas e formais que subjazem abordagens atuais acerca da modalidade em linguagem natural. O objetivo deste é promover um debate teórico de alguns componentes ontológicos e metodológicos que são muitas vezes tidos como conhecidos pela literatura atual neste tópico. Uma discussão sobre a evolução da linguagem em conexão com modalidade em termos de planejamento e deslocamento é promovida, seguida pelas discussões de Lewis e Stalnaker sobre a teoria de mundos possíveis. Finalmente, uma abordagem comparativa das perspectivas de Lewis e Stalnaker acerca de conhecimento e crença é construída para criar a base para leituras futuras no tópico de modais e evidenciais.

Palavras-chave: Modalidade; Evidencialidade; Filosofia da linguagem; Semântica formal

\section{Introduction}

The present work stems from the necessity of discussing key concepts within the ontology and the methodology of current approaches to modality in natural language - especially the ones connected to evidentiality - that frequently are taken for granted and are no longer lengthily discussed in the literature. Consequently, the aim here is to contextualize as well as hopefully clarify notions that remain puzzling as they fall between the cracks. Firstly, I will discuss biological concepts that connect human and language evolution to the phenomenon of modality, more specifically concerning planning and displacement. After that, Lewis's (1986) and Stalnaker's (1976) debates on possible worlds are addressed, as they underlie current approaches on natural language modality. Finally, concepts of knowledge and belief as discussed by
Lewis (1996) and Stalnaker (2006) are contrasted, in order to pave the way to a clearer view of current approaches on epistemic modality and its connection to evidence.

\section{Evolution, Thought and Language}

In their introduction to Evolution of Language: Biolinguistic Perspectives Larson, Depréz and Yamakido (2010:8) explore the concept of planning and how it could have come to exist in the evolution of man:

Anticipatory cognition, once acquired, can serve as the backdrop of action planning. It allows one to step away from present circumstances and abstractly project oneself in the not-yet-existent future. Plausibly, it represents a precursor of the language-unique ability for displacement and representation of future possible worlds (LARSON et al., 2010, p. 8). 
It is this "language-unique ability for displacement and representation of future possible worlds" that is of interest here, and how it relates to thought, perspectivism, internalism and I-language. The authors also call upon Bickerton (1981) and his isolation of this property of speaking of things that are not present to the speaker or to the hearer, this displacement, as a "crucial property driving early linguistic evolution" (LARSON et al., 2010, p. 12). In this same volume, Chomsky, Hauser and Fitch (henceforth CHF) differ from Bickerton mainly in terms of the acceptance of a gradual evolution of language on the latter's side, and a saltational and less selection-driven process on the former's. What they converge on, among other points, is the uniqueness of the creative ${ }^{1}$ aspect of human language.

Going back to the notion of displacement, it features in Hockett's (1960) list of Design Features of Human Language, pointing to the fact that human language goes beyond discussing the here and the now. Naming entities and referring to them when they are not present is one example of displacement, but not the type that is of interest here. Displacement within what von Fintel and Heim (2010, p.3) call intensional semantics, "the kind of semantics that models displacement of the point of evaluation in temporal and modal dimensions" is the type of displacement to be investigated here.

Modal displacement takes us to "a world distinct from the actual one, $[\ldots]$ a merely possible world" (VON FINTEL and HEIM, 2010, p.2). It can combine itself with other types of displacement - spatial or temporal, for example - and it can also talk about necessities and possibilities within this modal dimension, or about the world of evaluation. Even though modal markers are not necessary for us to discuss possibilities, overt marking of modal displacement has a special role. According to Kratzer,

markers of modal displacement provide a unique window into the interplay between grammar and other modules of cognition since they share properties with both quantifiers and degree expressions (KRATZER, 2013, p. 183).

For example, such modal displacement has, as one of its background processes, cognitive abilities such as planning. Regarding this ability, it is possible to connect modality to the point made by Gärdenfors and Osvath, who state that:

The ability to envision various actions and their consequences is a necessary requirement for an animal to be capable of planning. [...] An organism is

\footnotetext{
Due to the nature of this paper, I will not address the notion of creativity in connection to language at this moment.
}

planning its actions if it has a representation of a goal and a start situation and it is capable of generating a representation of partially ordered set of actions for itself for getting from start to goal. [...] planning therefore presupposes an inner world (LARSON et al., 2010, p. 105).

The authors have related this idea with evidence collected in digging sites, where artifacts were found in ways that point to future-oriented behaviors, such as burial of heavy tools and weapons in areas where animals would cross during migrations in order to hunt and field dress them faster when the season would come, among others. Connecting that to language, Kratzer affirms that:

The factual domain projection can be found in so many subareas of semantics suggests that it is a mechanism that relates to a very basic cognitive ability: a creature's ability to map a part of its own world to a range of worlds representing possible ways that part could be 'extended' to or 'grow into' a complete world (KRATZER, 2013, p. 192).

Going further, Chomsky (LARSON et al., 2010, p.56) comments on imaging studies that have lent "further support to the hypothesis that "there exists tissue in the human brain dedicated to a function of human language structure independent of speech and sound"'. According to this perspective, then, these findings could perchance corroborate the perspective in which evolution of language took place firstly on an internal level, as a language of thought, to later evolve into an external language, depending on other cognitive and biological systems and their corresponding evolution processes. Following this, the author comments that possible questions related to "which aspects of thought might be language-independent" arise, as well as to how these aspects would relate to the faculty of language and its systems. Modality, as pointed out by (KRATZER, 2013, p. 182), can also be language-independent, for

we do not need language to dwell in possibilities: babies do it, baboons do it, they say that even birds do it. We also do not need special words or moods to talk about possibilities.

It is of our concern here to explore modality in relation to these ideas and, in the course of this work, question the possibility of modality being, at its core, language-independent; reflecting on how it relates to the faculty of language in order to generate numerous expressions that deliver different degrees of possibility or necessity; and how it can pertain to other cognitive systems that have already been considered connected in some way to the language faculty, such as its connection 
to evidentiality. Converging, consequently, with Kratzer (2014, website):

From the time I started my dissertation work in New Zealand [...] I have been interested in context dependent semantic phenomena, in particular tense, modals, conditionals, quantifiers, and attitude ascriptions. One way of looking at this old interest from a more contemporary perspective is to see it as an interest in how the human language faculty interacts with nonlinguistic cognitive modules, some of which we may share with other species. The guiding idea behind this research is that most lexical items come with pointers to particular kinds of information that they request to be recruited from other cognitive components. The question is how those pointers are realized in natural languages, what kind of information they recruit, and how that information is ultimately integrated into the computation of meanings (KRATZER, 2014).

The discussion on modality is drenched in philosophical concepts - such as mind, thought, reality, their relationship to language as an internal property, as well as their relationship to an external language - which cannot be ignored, and are also the reasons why this work has been crafted this way, to step away from semantic or syntactic analysis of phenomena to look deeper into the ontological and methodological bases for the current approaches on this topic.

Next, concepts and works that underlie Kratzer's (2012) framework are going to be discussed, mainly concerning possible worlds and accessibility relations. Moreover, matters of knowledge and belief are going to be addressed in the last section, aiming to provide a foundation for further debate on the connection between modality and evidentiality in natural language as discussed in Kratzer (2012), Matthewson (submitted) among others.

\section{Possible Worlds}

Kratzer's framework for the analysis of modality in natural language takes from Lewis's $(1986,1998)$ possible worlds semantics machinery, as it is referred by von Fintel $(2006$, p. 3$)$. In the paragraphs that follow, the basic notions of this machinery according to Lewis (1986, $1998^{2}$ ) and Stalnaker (1976) are going to be outlined.

Work concerning possible worlds can be traced back to Leibniz, who claimed that "the universe - the actual world - is one of an infinite number of possible worlds

\footnotetext{
2 The works chosen to serve as basis for this section are by no means exhaustive on the topics, but have been chosen due to their cohesiveness in treating aspects of his theory that had been developed individually in other works, such as counterparts and quantification, for example. I refer to Lewis $(1968,1973,1975,1979 b, 1981)$ concerning discussions that, due to the nature of this work, do not figure here.
}

existing in the mind of God. God created the universe by actualizing one of these possible worlds - the best one" (STALNAKER, 1976, p. 65).

Lewis argues that, converging with basic human intuitions, we all believe things could have been different from how they actually are, perhaps even in countless ways. Ordinary language allows us to paraphrase it, as he points out (LEWIS, 1998, p. 96): "there are many ways things could have been besides the way they actually are", a sentence that is in itself what Lewis calls an existential quantification. By saying 'ways things could have been', what Lewis refers to as possible worlds. Worlds do not differ in kind amongst themselves, but in what happens in them, and the actual world is only one of such worlds. What makes it different from the other worlds, then? According to Lewis, it is 'actual' precisely because it is ours:

the meaning we give to 'actual' is such that it refers at any world $i$ to that world $i$ itself. 'Actual' is indexical, like 'I' or 'here', or 'now': it depends for its reference on the circumstances of utterance, to wit the world where the utterance is located (LEWIS, 1998, p. 97).

The thesis that our world is one option among many other worlds, the plurality of worlds, is what Lewis (1986, p.2) calls modal realism. Following the same indexical line of thought, present time is present because it is the time in which we are actually living, among the other possible times of the same kind, $t$ times.

Why would one subscribe to such modal realism, then? Lewis's (1986, p. 3) answer is that this hypothesis is
serviceable, and that is a reason to think that it is true. The familiar analysis of necessity as truth at all possible worlds was only the beginning. In the last two decades, philosophers have offered a great many more analyses that make reference to possible worlds, or to possible individuals that inhabit possible worlds. I find that record most impressive. I think it is clear that talk of possibilia has clarified questions in many parts of the philosophy of logic, of mind, of language, and of science - not to mention metaphysics itself. Even those who officially scoff often cannot resist the temptation to help themselves abashedly to this useful way of speaking.

According to Stalnaker (1976, p. 67), possible worlds as described by Lewis do not demand us to subscribe to a metaphysical theory because in our rationality or in our ordinary language we seem to commit to them. Instead, "what appears to be a weighty metaphysical theory is really just some ordinary beliefs by another name. Believing in possible worlds is like speaking prose. We have been doing it all our lives". 
The best application for this possible worlds machinery is, according to Lewis himself $(1986$, p. 5) to modality. It happens in terms of quantification, such as "possibly there are blue swans iff, for some world W, at W there are blue swans". "at W", signaling a world, would act as a modifier, mostly restricting the domain of the quantifier.

As it has been affirmed, "there are many ways things could have been besides the way they actually are" amounts to existential quantification, according to Lewis (1998, p.96). Existential quantification over the worlds refers to possibilities and necessity calls upon universal quantification - necessity refers to all worlds, and possibility, to some. Modal quantification is, nonetheless, restricted ${ }^{3}$ by accessibility relations, such as historical necessity, for example. This accessibility relation concerns worlds that, up to this moment, are identical (even if they may diverge in the next five minutes or much later on) - they are, thus, alternative possibilities for one another, relying on a relationship of similarity. Analogously, individuals within worlds have their alternative possibilities in other worlds, and these counterparts are under the same kind of restriction applied by accessibility relations to worlds - counterpart relations, also involving similarity.

Stalnaker (1976, p. 67) summarizes four theses that are contained in Lewis's approach to possible worlds. He defends a "more moderate form of realism about possible worlds - one that might be justified by our common modal opinions and defended as a foundation for a theory about the activities of rational agents". I will briefly outline these four theses and Stalnaker's acceptance or refusal of them, alongside his arguments, in the paragraphs that follow.

The first thesis, "possible worlds exist", can be accepted if taken to be, as Lewis affirmed, as the 'many ways things could have been', but not as worlds such as the actual one. Taking us to thesis two.

Thesis two affirms that "other possible worlds are things of the same sort as the actual world" (STALNAKER, 1976, p. 67). Stalnaker claims that this affirmation could have been derived from a misunderstanding between referring to the world as 'actual' and considering its indexicality as pointing to 'actual' as "I and all my surroundings", or perhaps even "the way things are". It can be argued, according to the author, that "the essential difference between our world and the others is that we are here, and not there" (1976, p. 69).

Thesis two leads to thesis three, which concerns itself with the indexicality of 'actual', placing it alongside

\footnotetext{
Epistemic is one of the types Lewis $(1986$, p. 8$)$ lists as restricted modalities, alongside nomological, historical necessity, deontic and "maybe one or two more".
}

other indexicals like 'I', 'here' and 'now', for example. Stalnaker claims that the problem with this third thesis is that it provides a neutral point of view - each world can be 'actual' if we do not consider a specific perspective in mind and take instead a completely objective, neutral one. In one sense, we go to perspectivism allied with Stalnaker's (1976, p. 69) claim that one should recognize that "the standpoint of the actual world is the absolute standpoint, and that it is part of the concept of actuality that this should be so", separating therefore the semantic analysis of 'actual' from any other metaphysical analysis that can be ascribed to it. By suggesting this moderate form of realism, consequently, Stalnaker accepts theses one and three, while rejecting thesis two.

Thesis four remains to be discussed, and it claims that "possible worlds cannot be reduced to something more basic" (STALNAKER, 1976, p.67). Regarding this thesis, the author argues that two distinct problems emerge and need to be separated:

The first is the general worry that the notion of a possible world is a very obscure notion. How can explanations in terms of possible worlds help us to understand anything unless we are told what possible worlds are, and told in terms which are independent of the notions which possible worlds are intended to explain? The second problem is the specific problem that believing in possible worlds and in the indexical analysis of actuality seems to commit one to extreme realism, which (many believe) is obviously false. Now to point to the difference between a way our world might have been and a world which is the way our world might have been, and to make clear that the possible worlds whose existence the theory is committed to are the former kind of thing and not the latter, is to do nothing to solve the first problem; in fact it makes it more acute since it uses a modal operator to say what a possible world is. But this simple distinction does, I think, dissolve the second problem which was the motivation for Adams's demand for an analysis (STALNAKER, 1976, p. 67).

Adams (1974) argued for a reduction of possible worlds to propositions. Stalnaker (1976, p. 71) proposes the reverse, "the analysis of propositions in terms of possible worlds", which is the one used in Kratzer's framework for natural language modality. Another fundamental adaptation concerns the necessity and possibility operators from modal logic when the same notions are to be analyzed in the semantics of natural language.

Necessity and possibility are expressed in classical modal logic via the operators box $(\square)$ and diamond $(\diamond)$. Despite their efficacy in the realms of logic, as Lewis (1986) affirms himself, such operators are not sufficient 
to account for the ambiguities and intricacies of ordinary, natural language. The author (1986, p. 13) claims that human language "has modal idioms that outrun the resources of standard modal logic"; no matter how many extensions and ad hoc measures one may take. Moreover, according to Portner (2009, p. 29), "modal logic does not integrate its ideas about the meanings of modal expressions into a general theory of natural language", and considering that the main goal of the semanticist is, according to the author, "to provide a precise theory of the meanings of modal expressions across languages", yielding descriptions of the facts and explaining "linguistically important generalizations", one must find different ways in which to work with modality within natural language semantics apart from boxes and diamonds ${ }^{4}$.

And that is precisely what the work of Kratzer $(1977,1979,1981,1986,1991,2012)$ does, as "the most influential incarnation of this idea" (VON FINTEL, 2006, p.3), 'this idea' being the use of the possible worlds machinery in the semantic analysis of modality within natural language.

Finally, before one is to turn to the linguistic framework per se, the concepts of 'epistemic', knowledge and belief as discussed by Lewis (1996) and Stalnaker (2006) are going to be presented, for they also underlie much of the current discussion on evidentials and modals.

As mentioned before, Lewis (1986, p. 27) characterizes an epistemic accessibility relation as one that targets the "content of someone's knowledge of the world", differing it from doxastic accessibility relations, which concern themselves with the speaker's beliefs ${ }^{5}$. The distinction between what is knowledge and what is belief, as well as how they can be related have been widely discussed in philosophy and are not the focus of the present work. However, I will outline Lewis's and Stalnaker's arguments concerning these two concepts and how they interact in terms of modality so that further discussion on this topic, such as the ones by Matthewson (in press) and von Fintel and Gillies (2010) analyses of evidentials and epistemic modals are contextualized.

\footnotetext{
4 I refer the reader to Lewis (1986) for a more detailed discussion of these operators.

5 Laca (2014, p. 77) argues for the elimination of the term 'epistemic' and the extension of doxastic accessibility relations: "Epistemic readings of modals express something about the information state and the beliefs of an epistemic agent - typically the Speaker. They operate on ignorance alternatives about what is or was the case, and not on the ways eventualities may comply or not with what is necessary or possible in view of a body of social norms, or preferences, or laws of nature. Given the fundamental link they entertain with the beliefs of an individual, they would be more appropriately called doxastic rather than epistemic, but the latter term is by now too well established to be changed".

6 This approach figures again in Matthewson's (in press) discussion of how evidence can in time become established knowledge.

7 This specific point in Lewis's argument can be connected to von Fintel and Gillies's (2010) argument concerning kernels and their relationship with evidence and knowledge, not approached here due to space restrictions.
}

\section{Knowledge and Belief}

In his Elusive Knowledge, Lewis (1996) claims that the apparent abundant and varied knowledge we (humans) all seem to have, concerning all kinds of things, is not necessarily all knowledge. One could say, calling upon an "ancient idea", as Lewis (1996, p. 550) does, that what marks the difference between knowledge and opinion (including true opinion) is justification - it is supported by reasons, then as ascriptions of knowledge would be context-dependent due to the fact that "standards for adequate justification" would also be context-dependent. However, Lewis does not subscribe to the idea that justification is what makes opinions into knowledge - it is not sufficient for one to have reasons and then declare something justified, therefore worthy of being referred to as 'known'.

At the same time, Lewis claims that justification is not always necessary; we gain knowledge by means that are not justified by non-circular arguments, such as through our perception, memory and testimony. Or we sometimes do not even know how we know something it might be that "we once had evidence, drew conclusions, and thereby gained knowledge; now we have forgotten our reasons, yet still we retain our knowledge ${ }^{6}$ " (Lewis 1996, p. 551). This particular point of Lewis's discussion is highly harmonious with what is discussed in Matthewson's work concerning the evidence sources and their trustworthiness, as well as general knowledge.

Lewis's conclusion on the matter is to break the connection between justification and knowledge. In order to do that, he first proposes that knowledge must be infallible: "subject $S$ knows proposition $P$ iff $P$ holds in every possibility left uneliminated by $S$ 's evidence; equivalently, iff $S$ 's evidence eliminates every possibility in which not- $P$ " $(1996$, p. 551). It does not matter who $S$ is or what his evidence is. The possibilities can be about how the whole world is, but can also be de se et nunc, they do not need to be limited to what is 'real', or only 'epistemic'. The author (1996, p. 552) claims - "S's epistemic possibilities are just those possibilities that are uneliminated by $S$ 's evidence" 7 .

What does it mean, however, to say that a possibility is uneliminated? It is here as well that Lewis's claims converge with Matthewson's and von Fintel and Gillies's works on evidentials and modality, respectively. Uneliminated possibilities are such "iff the subject's perceptual experience and memory in $W$ exactly match his perceptual experience and memory in actuality" (LEWIS, 1996, p.553). If perceptual evidence or memory eliminate a possibility, it is because the existence of the experience or memory actually conflicts with $W$. It is not about the propositional content of the 
experience being false - which can happen, but about the experience itself - the experience or memory's existence ${ }^{8}$.

For the sake of domain limitation, as well, there are possibilities that are ignored by us as irrelevant to the matter at hand. Lewis describes three rules concerning what possibilities cannot be ignored: the Rule of Actuality, the Rule of Belief and the Rule of Resemblance.

The Rule of Actuality concerns the fact that actuality "may never be properly ignored" (LEWIS, 1996, p. 554). The actuality in discussion is ours, no matter if we are ascribing knowledge to someone else; they technically are in the same actuality, provided that we exclude subject and time from the possibilities. We can even ascribe knowledge to counterparts in different possible worlds. In the end, Lewis (1996, p. 555) affirms that "it is the subject's actuality, not the ascriber's, that never can be properly ignored". It is $S$ 's knowledge that needs to be attended, if $S$ ignores possibilities $\mathrm{X}$ and $\mathrm{Y}$, we must also ignore them; conversely, if he can think of far-fetched yet uneliminated possibilities, we must do the same.

The Rule of Belief states that, despite if one is right or wrong in believing a possibility, such cannot be properly ignored. It is necessary, however, to insert a gradable notion of belief in this case - the belief needs to be sufficiently strong for the possibility to remain uneliminated. However, depending on context, even a low degree of belief strength could be considered high enough - thus eliminating few possibilities.

The Rule of Resemblance specifies that possibilities can resemble one another, rendering the fact that one cannot be ignored if it holds resemblance to an uneliminated possibility. If the subject's evidence does not eliminate a possibility, for example, similar evidence about another possibility also makes it uneliminated. However, the resemblance needs to be salient enough; consequently, "either every one of them [the possibilities] may be properly ignored, or else none may" (1996, p. 557).

Concerning what may be properly ignored, Lewis (1996, p. 558) formulates the Rule of Reliability. It is possible to say that possibilities concerning information transmitted to us via perception, memory and testimony are rather reliable. Their failure would thus allow us to potentially properly ignore a possibility. Vision, for example, is very reliable, and we tend to presuppose that it rarely fails.

Two Rules of Method follow. Firstly, we presuppose that samples are representatives - which can be defeasible,

\footnotetext{
8 Analogously, Matthewson (in press: 15), when discussing epistemic modals and their connection with evidence, argues: "[...] the reason epistemic modals have appeared to be about knowledge is perhaps simply because it is very normal to infer something about the speaker's knowledge from their assertions about their evidence".
}

nonetheless. We also tend to presuppose that "the best explanation of our evidence is the true explanation" (LEWIS, 1996, p. 558). Secondly, according to the Rule of Conservatism, we can adopt what is usually and mutually expected of us in terms of the presuppositions that are shared, what is common knowledge, and the possibilities that are known to be commonly ignored.

Lewis's final rule, the Rule of Attention, is more trivial: "a possibility not ignored at all is ipso facto not properly ignored" (1996, p.559). Particular contexts feature different possibilities, so one possibility can be properly ignored in a context and then move on to be uneliminated in a different context.

Such knowledge as the one molded by these rules is elusive, according to Lewis (1996, p. 562); it takes place by presupposing and ignoring, but it is nonetheless still knowledge even if of a nonclaimable sort - "presuppositions alone are not a basis on which to claim knowledge". However, knowledge that is based more on the elimination of not- $P$ possibilities is better than knowledge that bases itself on ignoring possibilities - if we start attending to previously ignored possibilities, knowledge is less stable due to our shift in attention.

Furthermore, concerning science and knowledge, the author states that
the serious business of science has to do not with knowledge per se; but rather, with the elimination of possibilities through the evidence of perception, memory, etc., and with the changes that one's belief system would (or might or should) undergo under the impact of such eliminations (LEWIS, 1996, p. 563).

In the end, Lewis (1996, p.566) claims that the cardinal principle of pragmatics - "interpret the message to make it make sense" - overrides every one of the rules he mentions. Last, but not least, I turn to Stalnaker's arguments on knowledge and belief, based on his $O n$ Logics of Knowledge and Belief (2006).

Starting off by contextualizing his approach, Stalnaker (2006, p. 169) affirms that "formal epistemology that develops a logic and formal semantics of knowledge and belief in the possible worlds framework began with Jaakko Hintikka's book Knowledge and Belief, published in 1962". Around the same time Hintikka published his book, Edmund Gettier also published his refutation of the analysis of knowledge as justified true belief, in 1963. Both works contributed immensely to renew discussions concerning knowledge and belief, and have been extended and adapted by many. The particular inner-workings of their analyses, even though by now outdated, provide insight to the general strategies by them devised, which still can provide insights into epistemological questions, according to Stalnaker (2006). 
The post-Gettier project of defining knowledge seeks to "clarify the abstract relationship between the concept of knowledge and some of the other concepts (belief and belief revision, causation and counterfactuals)", tools provided by formal semantic frameworks. Taking that into consideration, Stalnaker (2006) aims to establish a few connections that are present between the formal semantics frameworks and such notions as knowledge and belief. In order to do so, the author firstly discusses the basis of Hintikka's work:

The basic idea that Hintikka developed, and that has since become familiar, was to treat knowledge as a modal operator with a semantics that parallels the possible worlds semantics for necessity. Just as necessity is truth in all possible worlds, so knowledge is truth in all epistemically possible worlds. The assumption is that to have knowledge is to have a capacity to locate the actual world in logical space, to exclude certain possibilities from the candidates for actuality. The epistemic possibilities are those that remain after the exclusion, those that the knower cannot distinguish from actuality. To represent knowledge in this way is of course not to provide any kind of reductive analysis of knowledge, since the abstract theory gives no substantive account of the criteria for determining epistemic possibility (STALNAKER, 2006, p. 171).

The key point for this type of approach is to establish the features of the epistemic accessibility relation: it needs to be reflexive (necessary for knowledge to imply truth), transitive (knowing implies knowing that one knows), but not introspection (knowing that one lacks knowledge that one lacks). Conclusively and respectively, Hintikka accepts the KK and the S4 principles, while rejecting the S5 principle. His main concerns in his earlier models were directed at a single knower, not multiple ones as later works of epistemic models sought to address. Nonetheless, Hintikka's model has the potential to be extended to different knowers through generalization. What would be necessary, in this case, according to Stalnaker would be

[...] a separate knowledge operator for each knower, and in the semantics, a separate relation of epistemic accessibility for each knower that interprets the operator. One can also introduce, for any group of knowers, an operator for the common knowledge shared by the member of the group, where a group has common knowledge that $\phi$ if and only if all know that $\phi$, all know that all know that $\phi$, all know that all know that all know, etc. all the way up. The semantics for the common knowledge operator is interpreted in terms

\footnotetext{
9 Stalnaker (2006, p. 170).
}

of an accessibility relation that is definable in terms of the accessibility relations for the individual knowers: the common-knowledge accessibility relation for a group $\mathrm{G}$ is the transitive closure of the set of epistemic accessibility relations for the members of that group (STALNAKER, 2006, p. 174-175).

When discussing knowledge and belief, Stalnaker (2006, p. 179) affirms that the former implies the latter, and a strong concept of belief such as the one he pursues, in terms of subjective certainty, leads to the notion that when one believes, this implies the belief that one knows. His logic of knowledge and belief include, therefore, the principles of positive introspection, negative introspection, knowledge implies belief, consistency of belief and strong belief. Such combined logic, according to him (2006, p. 179), yields "a pure belief logic, KD45, which is validated by a doxastic accessibility relation that is serial, transitive and euclidean".

The outcome of this convergence - when defining belief in terms of knowledge - to the semantics would be that "one can define a doxastic accessibility relation for the derived belief operator in terms of the epistemic accessibility relation" (STALNAKER, 2006, p. 181). Supposing the epistemic accessibility relation and a relation of equivalence, Stalnaker's relations of subjective indistinguishability, knowledge and belief collapse into one.

The extension of a doxastic accessibility relation $(D)$ to an epistemic one $(R)$ can be done in two ways: minimally or maximally. Minimally, "the set of epistemically possible worlds for a knower in world $x$ will be the set of doxastically accessible worlds, plus $x$ " (Stalnaker 2006, p. 186). This implies adopting the analysis of knowledge as true belief. Even though this extension has its defenders, the author claims that it is necessary to impose stronger conditions on knowledge, moving on to the maximal extension - which "would not provide a plausible account of knowledge in general, but it might be the appropriate idealization for a certain limited context". This is due to its weaker logic in comparison to the one in the minimal extension, it allows one "to know things that go beyond one's internal states only when all of one's beliefs are correct" (2006, p. 186-7). The maximal extension follows from both positive and negative introspection conditions "that for any possible world $x$, all worlds epistemically accessible to $x$ will be subjectively indistinguishable from $x "(2006$, p. 186).

How about finding a definition of such accessibility relations somewhere between the minimal and the maximal extensions? Stalnaker (2006, p. 187) affirms that, in order to do that, one needs to enrich the theoretical tools available. One possibility of doing so would be to add a theory of belief revision, "and then to define knowledge as 
belief (or justified belief) that is stable under any potential revision by a piece of information that is in fact true ${ }^{10}$ ". This way, there would be a prior belief state, a function taking a proposition - new evidence - and then a posterior belief state. If this new information is compatible with the prior belief state, nothing changes, and the information is added to the prior beliefs; if the contrary happens, belief revision takes place.

Ultimately, the author (2006, p. 189) affirms that "we might define an epistemic accessibility relation in terms of the belief revision structure, and use it to interpret the knowledge operator in the standard way", epistemic accessibility would still extend doxastic accessibility. Still, a few alterations need to take place, for not all settings are as ideal as the one outlined by Stalnaker, who claims himself that this account for knowledge as it stands now might not be a plausible one in general.

In order to improve on his account, the author explores other features of the "relation between a knower and the world that may be relevant to determining which of his true beliefs count as knowledge" (2006, p. 191). Outside of an idealized setting, conditions are not fully normal and not all of the agent's beliefs are true. Looking into the interaction between the knower and the world, and how information is acquired, the knower can be misinformed in case one or more of his 'informants', i.e. "any kind of input channel" (2006, p. 192), is malfunctioning. When all informants are functioning properly, one may say the conditions are normal. Ultimately, according to the author:

Possible worlds in which conditions are fully normal will be those in which all the input channels are functioning normally - the worlds in the intersection of the two sets. This intersection will be the set compatible with the agent's beliefs, the set where belief and knowledge coincide. If conditions are abnormal with respect to informant one (if that information channel is corrupted) then while that informant may influence the agent's beliefs, it won't provide any knowledge. But if the other channel is uncorrupted, the beliefs that have it as their sole source will be knowledge (STALNAKER, 2006, p. 193).

This final rendition of Stalnaker's model can underlie discussions concerning epistemic modals and evidentials. Even though neither Matthewson nor von Fintel and Gillies have explicitly made this connection, I propose it here, taking as epistemic, i.e., knowledge, what Lewis and Stalnaker have converged upon, assuming its connection

\footnotetext{
10 This notion of stability when facing new evidence/information has been mentioned before concerning Lewis's discussion on knowledge and belief.
}

with belief. I further establish how it relates to evidentials in subsequent work.

This work has come to its conclusion, after having had punctually outlined and explored the ontological boundaries of current approaches in natural language modality and its connection to evidence, by means of making connections that had already been established between philosophical works and their linguistic expansions and adaptations explicit. In addition, new connections were proposed and the long established interface between philosophy and linguistics was hopefully strengthened.

\section{References}

ADAMS, R. M. Theories of Actuality. NOÛS, p. 211-231, 1974.

BICKERTON, D. Roots of Language. Ann Arbor: Karoma Publishers, 1981.

GETTIER, E. Is Justified True Belief Knowledge? Analysis, p. 121-123, 1963.

HINTIKKA, J. Knowledge and Belief: An Introduction to the Logic of the Two Notions. Ithaca: Cornell University Press, 1962.

HOCKETT, C. F. The origin of speech. Scientific American, p. 89-96, 1960.

KRATZER, A. What "must" and "can" Must and Can Mean. Linguistics and Philosophy, p. 337-355, 1977.

KRATZER, A. Semantik der Rede: Kontexttheorie, Modalwörter, Konditionalsätze. Kronberg: Scriptor, 1978.

KRATZER, A. Conditional Necessity and Possibility. In: BÄUERLE, R.; EGLI, U.; VON Stechow, A. Semantics from Different Points of View. New York: Springer, 1979. p. 117-147.

KRATZER, A. The Notional Category of Modality. In: EIKMEYER, H. J.; Rieser, H. Words, Worlds and Contexts. Berlin and New York: de Gruyter, 1981. p. 38-74.

KRATZER, A. Conditionals. In: vON STECHOW, A.; WUNDERLICH, D. Semantik/Semantics: An International Handbook of Contemporary Research. Berlin: de Gruyter, 1991. p. 651-656.

KRATZER, A. Modality. In: VON STECHOW, A.; WUNDERLICH, D. Semantik/Semantics: An International Handbook of Contemporary Research. Berlin: de Gruyter, 1991. p. 639-650.

KRATZER, A. Modality in Context. 2009.

KRATZER, A. Modals and Conditionals. New York: Oxford University Press, 2012.

KRATZER, A. Modality for the 21st Century. 19th International Congress of Linguists. Geneva, 2013. p. 181-201.

KRATZER, A. Angelika Kratzer. 2014. Retrieved from: < http:// people.umass.edu/kratzer/>.

KRATZER, A.; PIRES DE OLIVEIRA, R.; PESSOTTO, A. L. Talking about Modality: an interview with Angelika Kratzer. ReVEL, p. 8-20, 2014. 
LACA, B. Epistemic Modality and Temporal Anchoring. ReVEL, 76-105, 2014.

LARSON, R. K.; DÉPREZ, V.; YAMAKIDO, H. The Evolution of Human Language. Cambridge: Cambridge University Press, 2010.

LEWIS, D. Counterpart Theory and Quantified Modal Logic. Journal of Philosophy, p. 113-126, 1968.

LEWIS, D. Counterfactuals. Oxford: Blackwell, 1973.

LEWIS, D. Adverbs of Quantification. In: KEENAN, E. Formal semantics of natural language. Cambridge University Press, 1975. p. 3-15.

LEWIS, D. Probabilities of Conditionals and Conditional Probabilities. Philosophical Review, p. 297-315, 1976.

LEWIS, D. Scorekeeping in a Language Game. Journal of Philosophical Logic, p. 339-359, 1979a.

LEWIS, D. Counterfactual Dependence and Time's Arrow. NOÛS, p. 455-476, 1979 b.

LEWIS, D. Ordering Semantics and Premise Semantics for Counterfactuals. Journal of Philosophical Logic, p. 217-234, 1981.

LEWIS, D. On the Plurality of Worlds. Oxford: Blackwell, 1986.

LEWIS, D. Elusive Knowledge. Australian Journal of Philosophy, p. 549-567, 1996.

LEWIS, D. Possible Worlds. In: LAURENCE, S.; MACDONALD, C. Contemporary Readings in the Foundations of Metaphysics. Oxford: Blackwell, 1998. p. 96-102.
MATTHEWSON, L. Evidential Restrictions on Epistemic Modals. In: ALONSO-OVALLE, L.; MENENDEZ-BENITO, P. Epistemic Indefinites. Oxford: Oxford University Press. (in press).

MATTHEWSON, L. Evidence type, evidence location, evidence strength. In: LEE, C.; PARK, J. (submitted).

PORTNER, P. Modality. New York: Oxford University Press, 2009.

STALNAKER, R. A Theory of Conditionals. In: RESCHER, N. Studies in logical theory. Oxford: Blackwell, 1968. p. 98-112.

STALNAKER, R. Possible Worlds. NOÛS, p. 65-75, 1976.

STALNAKER, R. Context and content: essays on intentionality in speech and thought. Oxford: Oxford University Press, 1978.

STALNAKER, R. A Defense of Conditional Excluded Middle. In: HARPER, W. L.; STALNAKER, R.; PEARCE, G. Ifs. Dordrecht: Reidel, 1981. p. 87-104.

STALNAKER, R. On Logics of Knowledge and Belief. Philosophical Studies, p. 169-199, 2006.

VON FINTEL, K. Modality and Language. In: BORCHERT, D. Encyclopedia of Philosophy. 2. ed. Detroit: Macmillan Reference USA, 2006.

VON FINTEL, K.; GILLIES, A.S. Must... Stay... Strong! Natural Language Semantics, p. 351-383, 2010.

VON FINTEL, K.; HEIM, I. Intensional Semantics. Cambridge: MIT, 2010.

Recebido: 24 de novembro de 2015.

Aprovado: 02 de junho de 2016.

Contato: monawar.monica@gmail.com 